J. Clin. Chem. Clin. Biochem.

Vol. 25, 1987, pp. 675-679

(C) 1987 Walter de Gruyter \& Co.

Berlin - New York

\title{
Quantitative Abnormalities of Lipoprotein Particles in Multiple Myeloma
}

\section{By H. Hachem}

\section{Laboratoire de Biochimie Appliquée, Faculté des Sciences Pharmaceutiques, Toulouse}

\section{G. Favre}

Laboratoire de Biochimie, Groupe de Recherches en Cancérologie, Centre Claudius Regaud, Toulouse

N. Ghalim, P. Puchois, J.-C. Fruchart

S. E. R. L. I. A., Institut Pasteur, Lille and

G. Soula

Laboratoire de Biochimie Appliquée, Faculté des Sciences Pharmaceutiques, Toulouse

Laboratoire de Biochimie - Groupe de Recherches en Cancérologie, Centre Claudius Regaud, Toulouse, France

(Received February 2/July 27, 1987)

Summary: Serum concentrations of total cholesterol and lipoprotein cholesterol, of apolipoproteins A I and A II and of apolipoprotein A I in lipoprotein particles (Lp A I and Lp A) were determined in 43 patients with multiple myeloma.

There were striking alterations in the plasma levels of these analytes relative to normal subjects.

We observed a decrease of cholesterol levels in $\mathrm{LDL}, \mathrm{HDL}$ and $\mathrm{HDL}_{3}$ fractions, and of apolipoproteins $\mathrm{A}$ I and A II compared with normal subjects. The $\mathrm{HDL}_{2}$ cholesterol was increased.

The decrease of apolipoprotein A II was more prominent than apolipoprotein A I.

The decrease of apolipoprotein A I concerns only the A I (Lp A), while the A I (Lp A I) was increased.

Most of these modifications were correlated with the monoclonal Ig levels.

\section{Introduction}

Most patients suffering from multiple myelomatosis show disturbances in serum cholesterol and lipoproteins $(1-3)$. Fiessinger et al. (3) described a decrease in $\alpha$-lipoproteins and less frequently $\beta$-lipoproteins with hypocholesterolaemia in myeloma patients and suggested that these decreases were associated with progressive disease. We have observed that the same disease state is accompanied by decreases of HDL cholesterol and apolipoprotein A I concentrations which were inversely correlated with the monoclonal immunoglobulin level (4). These two parameters appear to play central roles in corporeal cholesterol metabolism. The presence of several HDL classes has been confirmed in many studies. In the studies of Gofman et al. (5) HDL was separated by ultracentrifugation based on density flotation into three subpopulations: $\mathrm{HDL}_{1}, \mathrm{HDL}_{2}$ and $\mathrm{HDL}_{3}$. Without doubt, $\mathrm{HDL}_{2}$ and $\mathrm{HDL}_{3}$ are the major $\mathrm{HDL}$ populations present in the plasma. As previously described, these 
subfractions could play distinct metabolic roles in pathological events $(6,7)$ or cellular cholesterol metabolism in vitro $(8,9)$. Apolipoprotein A I exists in at least two different types of lipoprotein particles in human plasma $(10,11)$. More than $50 \%$ of total apolipoprotein A I is associated with apolipoprotein A II (Lp A particles) while the rest exists in lipoproteins that contain no apolipoprotein A II (Lp A I particles). These two populations of particles apparently may represent two metabolically distinct pools of apolipoprotein A I-containing lipoproteins (11). The basis of the lower HDL cholesterol concentrations present in subjects with myelomatosis has not been previously elucidated. In view of the possibility of a distinct metabolic role for HDL-containing particles, it is of interest to determine which particle is involved in HDL pertubations in myeloma disease.

This study was undertaken to determine the level of cholesterol associated with LDL, HDL, $\mathrm{HDL}_{2}$ and $\mathrm{HDL}_{3}$, the circulating mass of apolipoprotein A I and A II, and the A I concentrations of lipoprotein particles containing A I associated or unassociated with A II (A I (Lp A) and A I (Lp A I)) in patients suffering from myeloma. These studies increase our understanding of the pathological events which occur in cholesterol metabolism in myeloma.

\section{Materials and Methods}

Clinical populations

Studies were performed on 43 patients with multiple myeloma (28 females and 15 males). The diagnosis was based both on bone marrow histology and on the presence of monoclonal Ig or light chain gammopathy. The monoclonal gammopatbies were IgG Kappa in 23 patients, IgG Lambda in 10 patients, IgA Lambda in 3 patients, IgA Kappa in 6 patients and Kappa light chains in one patient. The ages of the patients ranged between 40 and 60, except for 3 patients aged 75, 78, and 80 (10 patients between 40 and 50 years; 30 patients between 50 and 60 years).

On the basis of clinical examination and standard biological parameters of hepatic function (serum aspartate aminotransferase, alanine aminotransferase, lactate dehydrogenase, alkaline phosphatase and bilirubin), they were considered as having normal liver function at the time of the blood sampling.

Since initial analysis indicated no differences between male and female patients, the data for the two groups were combined for the statistical analysis.

Sixty eight healthy normolipidaemic subjects were used as controls for triacylglycerols and cholesterol, and thirty as controls for plasma apolipoprotein A I of lipoprotein particles (A I (Lp $A$ I) and A I (Lp A)) and for plasma apolipoproteins A I and A II. The age distribution of these two populations was in the same range as the myeloma patients.

Blood samples were obtained by venipuncture from subjects who had fasted overnight. The blood was collected in $10 \mathrm{ml}$ vacutainer tubes containing $0.5 \mathrm{ml}$ of $5 \mathrm{mmol} / \mathrm{l}$ EDTA, and centrifuged for $15 \mathrm{~min}$ at $2500 \mathrm{~min}^{-1}$ at $4^{\circ} \mathrm{C}$ to separate cells from plasma. Plasma samples were kept frozen for more than one month, at $-20^{\circ} \mathrm{C}$ until analysis. In these conditions, no significant lipid or apolipoprotein modifications were observed.

\section{Reagents}

Manganese chloride and heparin sodium salt were purchased from Sigma Chemical Company; and dextran sulphate $\left(M_{\mathrm{r}}=\right.$ 15000 ) was obtained from Sochibo $-3-5$, rue Carnot, 92100 Boulogne-sur-Seine, France). All other reagents were of analytical grade.

\section{Analytical methods}

Plasma cholesterol and triacyglycerol $(12,13)$ concentrations were determined by enzymatic methods. LDL cholesterol was determined by a precipitation method (BioMerieux, Marcyl'Etoile 69260 Charbonnieres les Bains, France) as was the cholesterol associated with $\mathrm{HDL}, \mathrm{HDL}_{2}$ and $\mathrm{HDL}_{3}$ (12).

Determination of apolipoproteins A I and A II and of $A I$ in lipoprotein particles ( $L p A$ and $L p A I$ )

Apolipoprotein A I and A II were determined by non-competitive enzyme-linked immunosorbent assay $(14,15)$.

The quantitative determination of A I (Lp A) and A I (Lp A I) was performed using an automated enzyme-linked differential antibody immunosorbent technique, on microtitre plates. The procedure is described in detail elsewhere (16).

Briefly, the method consisted of two assays:

a) Measurement of total apolipoprotein $\mathrm{A} I$ by non-competitive enzyme-linked immunoassay (14). Here, antibodies to apolipoprotein A I were coated on microtitre plates. After incubation with undelipidated plasma at various dilutions, the total amount of apolipoprotein A I retained by these first antibodies was evaluated using peroxidase-labeled antibodies to apolipoprotein A I (A I (Lp A) + A I (Lp A I)).

b) For the measurement of $A I$ ( $L p A)$, the plate wells were coated with antibodies to apolipoprotein A II. After incubation with samples, only A I (Lp A) lipoproteins were retained while A I (Lp A I) lipoproteins were removed in the washing process. The amount of apolipoproteins A I associated with A II was then evaluated by using again peroxidase labeled antibodies to apolipoprotein A I.

Apolipoprotein A I unassociated with A II was evaluated by substracting the concentration of A I (Lp A) from total A I.

The assay of apolipoprotein A I associated with A II was linear over the range of 0.005 to $0.05 \mathrm{~g} / \mathrm{l}$. Within- and between-assāy CVs were 5.6 and $9.8 \%$ respectively (16). LpA isolated from plasma from a normolipidaemic fasting subject was used as standard.

\section{Statistical studies}

A preliminary statistical study based on an $\mathrm{F}$ test indicates a discrepancy between the variances of controls and myeloma populations. Comparison of means was carried out by the Mann-Withney U-test. Spearman's test was used to identify significant $(p<0.05)$ relationships between parameters.

\section{Results}

Table 1 shows the results obtained for total cholesterol, HDL and HDL subfractions and LDL cholesterol. Whereas total cholesterol was not modified, 
Tab. 1. Comparative studies of total cholesterol, lipoprotein cholesterol and triacyglycerol concentrations (mean \pm SD) between myeloma patients and the control group.

NS : not significant

$*: \mathrm{p}<0.05$

$* *: \mathrm{p}<0.01$

$* * *: \mathrm{p}<0.001$

$* * * *: p<0.0001$

\begin{tabular}{lllllll}
\hline & $\begin{array}{l}\text { Total } \\
\text { cholesterol } \\
\mathrm{mmol} / \mathrm{l}\end{array}$ & $\begin{array}{l}\mathrm{HDL} \\
\text { cholesterol } \\
\mathrm{mmol} / \mathrm{l}\end{array}$ & $\begin{array}{l}\mathrm{HDL} \\
\text { cholesterol } \\
\mathrm{mmol} / \mathrm{l}\end{array}$ & $\begin{array}{l}\text { HDL } \\
\text { cholesterol } \\
\mathrm{mmol} / \mathrm{l}\end{array}$ & $\begin{array}{l}\text { LDL } \\
\text { cholesterol } \\
\mathrm{mmol} / \mathrm{l}\end{array}$ & $\begin{array}{l}\text { Triacyl } \\
\text { glycerols } \\
\mathrm{mmol} / \mathrm{l}\end{array}$ \\
\hline $\begin{array}{l}\text { Control group } \\
\mathrm{N}=68\end{array}$ & $5.65 \pm 1.00$ & $1.44 \pm 0.36$ & $0.21 \pm 0.19$ & $1.22 \pm 0.27$ & $3.75 \pm 0.89$ & $1.05 \pm 0.4$ \\
$\begin{array}{l}\text { Myeloma patients } \\
\mathrm{N}=43\end{array}$ & $\begin{array}{l}5.38 \pm 1.17 \\
\mathrm{NS}\end{array}$ & $\begin{array}{l}1.07 \pm 0.50 \\
* * *\end{array}$ & $\begin{array}{l}0.35 \pm 0.26 \\
*\end{array}$ & $\begin{array}{l}0.72 \pm 0.39 \\
* * * *\end{array}$ & $\begin{array}{l}2.63 \pm 1.11 \\
* * * *\end{array}$ \\
\hline
\end{tabular}

Tab. 2. Comparative studies of apolipoproteins A I and A II, A I (Lp A I) and A I (Lp A) concentrations (mean \pm SD) between myeloma patients and the control group.

$*: \mathrm{p}<0.05$

**: $: \mathrm{p}<0.001$

$* * *: \mathrm{p}<0.0001$

\begin{tabular}{lllll}
\hline & $\begin{array}{l}\text { Apolipoprotein A I } \\
\mathrm{g} / \mathrm{l}\end{array}$ & $\begin{array}{l}\text { Apolipoprotein A II } \\
\mathrm{g} / \mathrm{l}\end{array}$ & $\begin{array}{l}\text { A I (Lp A I) } \\
\mathrm{g} / \mathrm{l}\end{array}$ & $\begin{array}{l}\text { A I (Lp A) } \\
\mathrm{g} / \mathrm{l}\end{array}$ \\
\hline $\begin{array}{l}\text { Control group } \\
\mathrm{N}=30\end{array}$ & $1.31 \pm 0.25$ & $0.44 \pm 0.08$ & $0.43 \pm 0.28$ & $0.83 \pm 0.20$ \\
$\begin{array}{l}\text { Myeloma patients } \\
\mathrm{N}=43\end{array}$ & $\begin{array}{l}1.05 \pm 0.37 \\
* *\end{array}$ & $\begin{array}{l}0.21 \pm 0.07 \\
* * *\end{array}$ & $\begin{array}{l}0.55 \pm 0.20 \\
*\end{array}$ & $\begin{array}{l}0.50 \pm 0.21 \\
* * *\end{array}$ \\
\hline
\end{tabular}

the HDL cholesterol levels were significantly decreased ( $p<0.001 ;$ tab. 1$)$ in myeloma patients. The mean and SD of HDL cholesterol levels were 1.07 $\pm 0.50 \mathrm{mmol} / 1$ compared with $1.44 \pm 0.36 \mathrm{mmol} / 1$ in healthy subjects. This decrease affected particularly the $\mathrm{HDL}_{3}$ subfraction $(\mathrm{p}<0.001)$; the $\mathrm{HDL}_{2}$ cholesterol was increased in myeloma $(p<0.001)$. This finding and the lower LDL cholesterol levels ( $p<0.0001$ ); $70 \%$ of cases) suggest that VLDL cholesterol must be elevated in this disease. Indeed approximate VLDL cholesterol concentrations (obtained by total cholesterol minus HDL cholesterol plus LDL cholesterol) were higher in myeloma patients $(1.64 \pm 0.78 \mathrm{mmol} / 1$ compared with 1.23 $\pm 0.49 \mathrm{mmol} / 1$ in control group, $p<0.01$ ):

Consistent with this proposal is the observation that the myelloma patients have significantly higher plasma triacyglycërol levels $(1.45 \pm 0.6 \mathrm{mmol} / \mathrm{l}$; $\mathrm{p}<0.01)$ than controls $(1.05 \pm 0.4 \mathrm{mmol} / \mathrm{l})$.

The plasma concentrations of both apolipoproteins A I and A II, and A I associated with A II (A I (Lp A) were significantly decreased in myeloma ( $<<0.01 ;$ tab. 2). The apolipoprotein A II levels ( $86 \%$ of cases, $p<0.0001$ ) were more diminished than apolipoprotein A I ( $44 \%$ of cases, $p<0.001$; tab. 2). This was consistent with the observation that, unlike A I (Lp A), the A I (Lp A I) levels were actually higher in myelomatosis ( $p<0.05$; tab. 2).

Plasma A I ( $L p$ A I) and A I ( $L p$ A) concentrations correlated positively with the cholesterol content of $\mathrm{HDL}, \mathrm{HDL}_{2}$ and $\mathrm{HDL}_{3}$ (tab. 3). The proportion of these two types of particles varied with the ratio of $\mathrm{HDL}_{2}$ and $\mathrm{HDL}_{3}$ in the plasma (11). In the same manner, the plasma A I (Lp A I) concentrations were

Tab. 3. Degree of significant linear association ( $r$ ) among LDL cholesterol, HDL cholesterol, A I (Lp A I), and A I (Lp A) with the cholesterol of lipoprotein fractions in myeloma patients.

$* \mathrm{p}<0.001$

$* *: p<0.0001$

\begin{tabular}{|c|c|c|c|}
\hline \multicolumn{2}{|l|}{ Parameters } & \multirow{2}{*}{$\frac{r}{0.678}$} & \multirow{2}{*}{$\frac{\mathrm{p}}{* *}$} \\
\hline HDL-Chol & vs $\mathrm{HDL}_{2}-\mathrm{Chol}$ & & \\
\hline HDL-Chol & vs $\mathrm{HDL}_{3}$-Chol & 0.839 & ** \\
\hline A I ( $\operatorname{Lp} A I)$ & vs HDL-Chol & 0.718 & $* *$ \\
\hline A I (Lp A I) & vs $\mathrm{HDL}_{2}$-Chol & 0.548 & $*$ \\
\hline A I (Lp A I) & vs $\mathrm{HDL}_{3}$-Chol & 0.550 & $*$ \\
\hline $\mathrm{A} I(\mathrm{Lp} A)$ & vs HDL-Chol & 0.877 & ** \\
\hline$A I(L p A)$ & vs $\mathrm{HDL}_{2}-\mathrm{Chol}$ & 0.502 & $*$ \\
\hline A I (Lp A) & vs $\mathrm{HDL}_{3}$-Chol & 0.851 & $* *$ \\
\hline
\end{tabular}


positively correlated with A I ( Lp A) concentrations $(r=0.681 ; p<0.001)$, while the $\mathrm{HDL}_{2}$ cholesterol was not correlated with the $\mathrm{HDL}_{3}$ cholesterol. No relationship is noticed between LDL cholesterol and the other parameters.

Table 4 shows an inverse relationship between the monoclonal Ig levels and the plasma apolipoproteins A I and A II, and the A I (Lp A I), A I (Lp A), HDL and $\mathrm{HDL}_{3}$ cholesterol concentrations. The increase in cholesterol $\mathrm{HDL}_{2}$ concentration was monoclonal Ig-independent. However, the small number of alpha chain myeloma cases $(n=9)$ made it impossible to determine whether there was a correlation between Ig isotype and the disturbed parameters.

Tab. 4. Degree of linear association (r) among monoclonal Ig with apolipoproteins A I and A II, A I (Lp A I), A I $(\mathrm{Lp} \mathrm{A})$ and with the cholesterol of lipoprotein fractions in myeloma patients.

$*: \mathrm{p}<0.05$

$* *: \mathrm{p}<0.01$

$* * *: \mathrm{p}<0.001$

\begin{tabular}{|c|c|c|}
\hline Ig vs & $\mathbf{r}$ & $\mathrm{p}$ \\
\hline Apolipoprotein A I & -0.512 & *** \\
\hline Apolipoprotein A II & -0.496 & ** \\
\hline A I (Lp A I ) & -0.342 & $*$ \\
\hline A I (Lp A) & -0.528 & $* * *$ \\
\hline LDL-cholesterol & -0.320 & * \\
\hline HDL-cholesterol & -0.559 & *** \\
\hline $\mathrm{HDL}_{2}$-cholesterol & -0.233 & NS \\
\hline $\mathrm{HDL}_{3}$-cholesterol & -0.583 & *** \\
\hline
\end{tabular}

\section{Discussion}

Our data showed significant decreases of LDL, HDL and $\mathrm{HDL}_{3}$ cholesterol, of apolipoproteins $\mathrm{AI}$ and A II and of A I (Lp A) in the plasma of patients with myelomatosis. In contrast with previous reports (1, $3)$, total plasma cholesterol was not significantly affected by the disease.

Increased elimination rates of $\beta$-lipoprotein and $\alpha$ lipoprotein by the reticuloendothelial system following complex formation with the pathological globulin in the plasma might be the basis of the reduced plasma LDL- and HDL-cholesterol concentrations in our patients, as suggested by Fiessinger et al. (3). This hypothesis has never been confirmed in vivo and indeed identical lipid perturbations occur in the other haematological diseases such as leukaemia (17), a disease that does not show abnormal immunoglobulin synthesis. Bases \& Krakoff demonstrated increased phagocytic activity of the reticuloendothelial system in patients with chronic myeloproliferative disorders and hypocholesterolaemia (18) without complex formation of lipoprotein with pathological globulin in the plasma. In the same disease, Ginsberg et al. (19)。 observed reduced LDL cholesterol concentrations and suggested that these were associated with increased non receptor-mediated catabolism of LDL apolipoprotein $\mathrm{B}$. If the reduced LDL-cholesterol in myeloma was due to increased activity of the reticuloendothelial system, why is an identical process not involved in HDL metabolism? Indeed, we have observed an increase of cholesterol in $\mathrm{HDL}_{2}$ without association with the tumoral mass expressed by the pathological immunoglobulin levels. These observations suggest that a more specific mechanism is likely for the reduced LDL concentrations of patients with myeloma disease, based on increased LDL receptormediated uptake and degradation of LDL. Cells that have undergone malignant transformation are known to have altered cholesterol metabolism $(20,21)$, and low LDL cholesterol levels in patients with acute leukaemia are the result of increased receptor-mediated LDL uptake and degradation by leukaemic cells as suggested by Vitols et al. (17). An increased load of myeloma plasmocyte cells could conceivably alter plasma cholesterol levels, and the marked decreases of cholesterol concentrations in HDL, particularly into $\mathrm{HDL}_{3}$, were consistent with an LDL receptordependent process. Oram (9) demonstrated in cultured human fibroblasts and human arterial smooth muscle cells, that exposure of cells to $\mathrm{HDL}_{3}$ and VHDL removes cholesterol from cells and also results in elevated LDL receptor activity and an enhanced rate of LDL degradation by the cells.

We can suppose that in myeloma patients, the decreased cholesterol $\mathrm{HDL}_{3}$ levels wैere due to $\mathrm{HDL}_{3}$ cellular interaction. This interaction of $\mathrm{HDL}_{3}$ with tumour plasmocyte cells results in a rapid increase in LDL receptor activity in parallel to an increase in the rate of cholesterol synthesis and a decrease in the rate of cholesterol esterification, as suggested by several authors $(22,8)$ for cultured human fibroblasts. The correlations observed in our patients between cholesterol levels or $\mathrm{LDL}$ and $\mathrm{HDL}_{3}$ with the disease state supports this hypothesis. It has been postulated that the efflux of cholesterol from the cell is mediated by the binding of HDL to high-affinity sites $(22,23)$. Recent work by Fielding et al. (24) has indicated that sterol efflux from fibroblasts is dependent upon a minor lipoprotein fraction containing apolipoprotein A I unassociated with other major lipoproteins. The increased mass of circulating A I (Lp A I) observed in our patients in relation to the disease state support this hypothesis. The increased $\mathrm{HDL}_{2}$-cholesterol in our patients would be explained by the availability of lipid transport proteins that may "drive" the cholesterol transport process (28). The decrease of total plasma apolipoprơtein A I (activator of lecithin-cho- 
lesterol acyltransferase) might induce a decrease of lecithin cholesterol acyltransferase and an increase of apolipoprotein E-rich HDL (25). Fielding et al. (26) have demonstrated that unassociated apolipoprotein E promotes sterol efflux. At that time, however, data on apolipoprotein $\mathrm{E}$ levels in myeloma were not available.

Elsewhere we cannot rule out the hypothesis that myeloma HDL have altered structure with an accompanying increase in their catabolism. These structural modifications could result from substitution of apolipoproteins A I and A II by another protein resulting from the disease. This phenomenon of one apolipoprotein displacing another has been shown by several authors $(27,28,29)$.

Preliminary results in our laboratory have shown the presence of serum amyloid A protein (SAA) in myeloma HDL. Parks et al. (30) have described, in a non-human primate, a displacement of A I, A II or $\mathrm{C}$-apolipoproteins from HDL after induction with serum amyloid A protein.

We think that the presence of serum amyloid A protein could modulate the HDL surface and conse-

\section{References}

1. Seitanidis, B. A., Shulman, G. \& Hobbs, J. R. (1970) Clin. Chim. Acta 29, 93-95.

2. Shulman, S. R., Lynch, S. R., Bezwoda, W. R. \& Gilich, G. C. (1976) J. Clin. Pathol. 29, 458-461.

3. Fiessinger, J. N., Olier, M. P., Filitti-Wurmser, S. \& Hartmann, L. (1971) Ann. Biol. Clin. 29, 25-37.

4. Hachem, H., Favre, G., Raynal, G. \& Soula, G. (1983) Ann. Biol. Clin. $41,181=185$.

5. Gofman, J. W., De Lalla, O., Glazier, F., Freeman, N. K., Lindgren, F. T., Nichols, A. V., Strisower, E. H. \& Tamplin, A. R. (1954) Plasma 2, 413-484.

6. Enzi, G., Favaretto, L., Martini, S., Sellin, R., Baritussio, A., Baggio, G. \& Crepaldi, G. (1983) J. Lipid. Res. 24, $566-574$

7. Mendonza, S., Lumer, R. F., Glueck, C. F., Chen, C. Y., Steiner, P. M., Sallat, R. W. \& Kashyab, M. L. (1976) Atherrosclerosis $25,131-136$.

8. Oram, J. F., Albers, J. J., Cheung, M. C. \& Bierman, E. L. (1981) J. Biol. Chem. 256, 8348-8356.

9. Oram, J. F. (1983) Arteriosclerosis 3, 420-432.

10. Norfeldt, P. P., Olofsson, S. O., Fager, G. \& Bondjers, G. (1981) Eur. J. Biochem. 118, 1-8.

11. Atmeth, R. F., Shepherd, J. \& Packard, C. J. (1983) Biochim. Biophys. Acta 751, 175-188.

12. Gidez, L. I., Miller, G. J., Burstein, M., Slagle, S. \& Eder; A. H. (1982) J. Lipid. Res. 23, 1206-1222.

13. Bucolo, G. \& David, H. (1973) Clin. Chem. 19, 476-482.

14. Koren, E., Puchois, P., Mc Conathy, W. J., Fesmire, J. D. \& Alaupovic, P. (1985) Clin. Chim. Acta 147, 85-95.

15. Puchois, P., Kandoussi, A., Duriez, P. \& Fruchart, J. C. (1986) J. Immunoassay 7, 285-307.

16. Koren, E., Puchois, P., Alaupovic, P., Fesmire, J., Kandoussi, A. \& Fruchart, J. C. (1987) Clin. Chem. 33, 3843. quently facilitate the binding of HDL via specific sites to tumour cells. The decrease of apolipoproteins A I and A II, particularly of A I ( $L p$ A) with relation to disease state could conceivably support this hypothesis. At least, these two apolipoproteins (A I and A II) are localized at the periphery of the lipoprotein particle (31).

Studies are in progress in our laboratory to delineate the mechanism involved in the production of these perturbations in patients suffering from myeloma.

Our results suggest that determination of apolipoprotein A I, associated or unassociated with A II, provide information that may be of value in assessing myeloma disease activity.

\section{Acknowledgement}

We are indebted to Dr P. Cambon (Centre Antoine Lacassagne, Nice, France) for the gift of major myeloma samples. The secretarial aid of Jeanine Leon is also appreciated.

This work was supported by a grant of the "Comités Départmentaux (Région "Midi-Pyrénées) de la Ligue Nationale de Lutte Contre le Cancer".

17. Vitols, S., Gahrton, G., Bjorkholm, M. \& Peterson, C. (1985) Lancet $I$ or $I I, 1150-1153$.

18. Bases, R. E. \& Krafoff, I. H. (1965) J. Reticuloendothel. Soc. 2, 1-7.

19. Ginsberg, H., Goldberd, I. J., Wang-Iverson, P., Gilter, E., Le, N. A., Gilbert, H. S. \& Brown, W. V. (1983) Arteriosclerosis 3, 233-241.

20. Chen, H. W. \& Hemiger, H. (1974) Cancer Res. 34, 13041307.

21. Betteridge, D., Krone, J. W., Ford, J. M. \& Galton, D. J. (1979) Eur. J. Clin. Invest. 9, 439-441.

22. Briesbroeck, R., Oram, J. V., Albers, J. J. \& Bierman, E. L. (1983) J. Clin. Invest. 71, 525-539.

23. Wu, J. D., Butler, J. \& Bailey, J. M. (1979) J. Lipid. Res. $20,472-480$.

24. Fielding, C. J. \& Fielding, P. E. (1981) Proc. Natl. Acad. Sci. USA 78, $3911-3914$.

25. Harry, D. S., Day, R. C. \& Bwen, J. S. (1978) Scand. J. Clin. Lab. Invest. 38, suppl. 150, 223-227.

26. Fielding, C. J., Frohlich, J., Moser, K. \& Fielding, P. E. (1982) Metabolism 31, 1023-1028.

27. Lagocki, P. A. \& Scanu, A. M. (1980) J. Biol. Chem. 255, $3701-3706$.

28. Coetzee, G. A., Strachan, A. F., Van Der Westhuylen, D. R., Hoppe, E. C., Jeenah, M. S. \& De Beer, F. C. (1986) J. Biol. Chem. 261, 9644-9651.

29. Pownall, H. J., Pao, Q., Rohde, M. \& Gotto, A. M. (1978) Biochim. Biophys. Res. Commun. 85, 408-414.

30. Parks, J. S. \& Rudel, L. L. (1985) J. Lipid Res. 26, 8291.

31. Shen, B. W., Scanu, A. M. \& Kezdy, F. J. (1977) Proc. Natl. Acad. Sci. USA 74, 837-841.

Georges Soula

Centre Claudius Regaud

20-24 rue du Pont Saint-Pierre

F-31052 Toulouse Cedex 
